\title{
Inheritance and Innovation of Engineering Management Informatization
}

\begin{abstract}
In the life-cycle of large projects, the operational phase lasts the longest, costs the most and substantially benefits the project. During the whole phase, energy, material and human resources may cost a lot. Effective control of such costs is one of the main targets of engineering management informatization. How to lower the organization collaboration cost in project management and how to support effective collaboration among different areas, organizations and departments in the ways of technology and management are major goals in engineering management informatization. In the phase of project operation, project owners, partners and customers are the stakeholders of engineering management informatization. Through the case of airport management informatization, inherited and innovation of engineering management informatization will be discussed. It is illustrated that airport informatization is the innovation of business model and technology applications through the analysis and study on cases of airport informatization.
\end{abstract}

Keywords: engineering management, informatization, inter-organizational relationship, management creation, resource sharing

\section{Introduction}

Engineering management informatization is based on the inheritance and innovation of enterprise management informatization. Effective implementation of informatization could help all parties involved in projects to realize high-efficiency communication and collaboration through information sharing. He (2013) sums up the core thought of engineering management as "people-oriented, harmony between nature and humanity, collaborative innovation, building a harmony among people, society and nature" (p.4). Zhu (2008) mentioned that "Engineering management informa-

Manuscript received December 5, 2013; accepted March 5, 2014

Kai Sun, Ren-huai Liu (凷

Jinan University, Guangzhou 510632, China

Email:1rh@jnu.edu.cn tization is one of the fields of informatization and is also a kind of tools for engineering management (p.32). Sun and Liu (2012) realized that "without the realization of relevant enterprise informatization, engineering management informatization can't be realized" (p.2).

From an inheritance point of view, engineering management informatization and enterprise management informatization are based on the same technical model and have the same theoretical basis. Thus, it is possible to draw upon each of their strong points and learn from each of them to realize specific application on the basis of a common planning implementation framework. In terms of technological implementation, these two sorts of informatization address different topics and are realized in different ways, but ultimately both of them solve the issues of information communication and sharing using similar methods and application modes. In addition, one project is always involved in various enterprises so broad engineering management informatization also includes informatization of various relevant organizations such as project construction enterprises and operation enterprises. It's also the link and inheritance of two sorts of informatization.

From an innovation point of view, enterprise management informatization focuses more on its own informatization and emphasizes its own information infrastructural construction as well as optimization of internal business process. The implementation process of its internal platform mainly aims at operation and control. However, engineering management informatization is more focused on information resource sharing among many organizations and the integration of relevant business processes. With regard to information infrastructural construction, engineering management informatization is more focused on utilizing external public infrastructure and its implementation process of inter-organizational platform mainly emphasizes collaboration and sharing. It is typical inter-organizational information system application.

The primary principle of engineering management informatization is the optimization of a project's life-cycle, not the optimization of phases, especially not the construction phase. Liu and Sun (2011) suggest that "the planning of en- 
gineering management informatization belongs to inter-organization planning and should fully takes collaboration and communication of project different stages, fields, organizations and departments into consideration" (p. 4).

Enterprise informatization or single organization informatization focuses on internal planning. During the process of planning and implementation, its main feature is to consider the full application of an organization's resources while the main feature of engineering management informatization takes on external planning during the process of planning and implementation. The informatization process should take a comprehensive point of view and fully investigate and analyze all project stakeholders. In doing this, it can deeply understand all parties' demand and investigate available resources. Informatization is based on available resources of all projects stakeholders to plan the implementation process not only on the resource realization of single organization. On the theory and approach, internal planning and external planning are interlinked but are different from a resource point of view. The former is more focused on organizing internal communication and control while the latter is more on inter-organizational relationships and matching.

\section{Inter-organizational matching of engineer- ing management informatization}

Informatization runs through specific product life-cycle from demonstration, design, construction, operation to discard. Different phase have different participants and face different principal contradictions. Sun (2012) realized that "in the different phase of life-cycle, since organization strategy is varied with each participant who holds different interests, defines and understands the relevant concept differently, the un-matching phenomenon will appear in the engineering management"'(p.28).

\subsection{Statement of problem}

During the life-cycle of the project, organization strategy is varied with each participant who holds different interests and management ideas. Take the case of a project operation organization and a project construction organization for example. These two types of organization are varied with the use of current engineering management methods, multi-project management methods, product life cycle management methods, and interface management. They also have different definitions on the management elements.

Project operation organization mainly adopts the method of program management. According to the definition of the Project Management Institute (PMI), a program is a group of inter-related projects requesting coordinated management to obtain benefit which can't obtain from the single project. Program management takes project management as its core and generally controls and coordinates many projects.

However, project construction organization mainly adopts project portfolio management. PMI's definition of project portfolio management is to select and support many projects or program investments under the guidance of available resources and an enterprise strategy plan. Project portfolio management ensures projects conform to the enterprise's strategy target and realize the maximization of business income by evaluating, selecting, combining, and optimizing projects.

It's clearly seen from the above definition that for project operation organization, its management target is how to ensure the effective collaboration of participants of single project program to complete the project target with respect to time, quality and quantity. For project construction organization, it should reasonably and effectively allocate the resources from its involved many projects and lower operation cost.

For life cycle management, the definition of project operation organization is the overall process of one physical project from design, construction and operation, to discard while the definition of project construction organization is the contract cycle of involved project programs.

In terms of interface management, project operations organizations focus not only on interface management for all project participants but also on the timing of interface management for the transition of different project phases. Project construction organizations focus on interface coordination management among operation organizations and other relevant organizations as well as on the coordination management and resource sharing of the internal organization among different projects.

\subsection{Inter-organizational matching}

Study on inter-organizational matching helps advance the level of engineering management informatization. The informatization implementation process emphasizes higher degrees of matching among each organization and organized business and information systems. Higher degrees of incompatibility correspond to higher costs of maintaining an inter-organizational relationship and larger negative impacts on projects. Thus, these factors influence the organizational performance of each party. Sun and Liu (2013) indicated that "how to identify the un-matching elements of each phase in the phase of project life cycle, effectively eliminate un-matching phenomenon among organizations, how to analyze and evaluate the matching degree of inter-organization; how to plan reasonable engineering management organization framework to avoid most of un-matching phenomenon. All these key points and problems should be focused on and solved during the informatization process" (p.294).

Engineering management informatization is indispensable to effective application of information technology. Nowadays, information technology develops rapidly and various technical solutions have ripened. Ripened information technology processing capacity, to a certain extent, is able to satisfy all project demands. During the project life cycle, 
problems during the process of informatization are management problems caused by non-technical factors. Most of these management problems can be attributed to matching problems of different fields and units. For engineering management informatization, matching problems are expanded to mutual adjustment and matching among many organizations, departments and projects.

\section{Engineering operation management infor- matization-case of airport industry}

During the life cycle of engineering management, project operation management requires the longest time cycle and accounts for the largest cost ratio (around 80\%). The project operation period, namely the public service period, has a huge environmental impact and produces social and economic benefits. The significance to carry out a systematic and deep study on the informatization problems during project operation period is obvious. Through the case of the airport management informatization, the informatization problems of project operation phase has been analyzed and discussed.

China's civil aviation has become the second largest air transport system second to the United States in the world. The development of Chinese airport industry has just begun unfolding. During the "Eleventh Five-Year Plan" period, the total rebuilding and expanding of airports are 53 in 10 provinces, autonomous regions and centrally administered municipalities, with total investment of RMB68.198 billion. In accordance with the planning of Civil Aviation Administration of China, the total number of national transportation airports will reach more than 230 by 2015 , which will cover $94 \%$ economic aggregate, $83 \%$ population and $81 \%$ county administrative units.

Among 2010 Passenger Capacity Rankings of Global Busiest Airports, Beijing Capital International Airport, Hong Kong International Airport, Shanghai Pudong International Airport and Guangzhou Baiyun International Airport respectively rank the second, 11th, 19th and 20th. Among 2010 Composite Index of Airport Quality Rankings composed of service quality and passenger's satisfaction, Hong Kong International Airport, Beijing Capital International Airport, Shanghai Pudong International Airport and Guangzhou Baiyun International Airport respectively rank the third, fifth, sixth and 18th. When large-scale airport has edged into the advanced ranks in the world, small and medium airports also takes on widespread vitality.

Since 2001 each airport of CAAC has successively been converted to use localization management. The airport is better integrated into the local social economic life and become important projects for local development, solving the employment and boosting the people's livelihood. Meanwhile the internal restructuring of airport industry is also continuously carrying out. Original single and centralized management has created a business diversification management pattern characterized by decentralized and specializa- tion, which request a higher level of informatization construction.

\subsection{Evolution of airport conception}

People's understanding of the conception the airport is constantly changing. The word airport defines in the traditional sense as a tract of leveled land where aircraft can take off, land and taxi with adjacent buildings and facilities. Its function is to provide the relevant service to the aircraft, passengers and cargo owners. From this description, an airport in the traditional sense only has the single function of air transportation. Its operation model and setting of business process is centered on basic air services.

With the ever increasing function of an airport as an important part of modern society, people have new understanding of airports. Just as in the description in the relevant report of ACI (airport council international, ACI), the airport is valuable to its surrounding community, it is able to assist the community to exploit new economic potentialities to ensure stable growth and could support its long-term development and provide more employment opportunities. The modern airport is fused with its surrounding environment. Airports share a mutual coordinated development in promotion and common prosperity with local cities and regions as well as correlated industries.

The generation of the modern airport management model is mainly from the influence by constant change of business, management and technology, as shown in Figure 1.

In the aspect of business, the increase of non-air services leads to increasing complexity of airport operation management. Airport commercial model is gradually changing from self-operation to specialization.

In the aspect of administration, as a consequence of the increase of non-traditional business lines and enhancement of outsourcing, the airport operation model is also changed from centralized management to decentralized management, which is more reliant on effective cooperation among stakeholders.

In the aspect of technology, Sun and Lai (2012) realized that "as a result of constant changes of information technology, various information systems in the airport are increasingly complex and the stand-alone operation is developed into the operations of integration and netization" (p.55).

Airport informatization is the typical case of informatization of project operation management phase in the project life cycle. Its implementation process is different from traditional conception of resources integration and is innovation of information sharing means. Informatization realization process is also the process of reforming the airport operation model. With the change of operation management model and wide application of information technology, the utilization modes and approaches have been changed greatly. Boosting the core competitiveness of airport can be realized by fully utilizing various available resources and increasing the service efficiency of resources, and consequently more benefits could be obtained by 


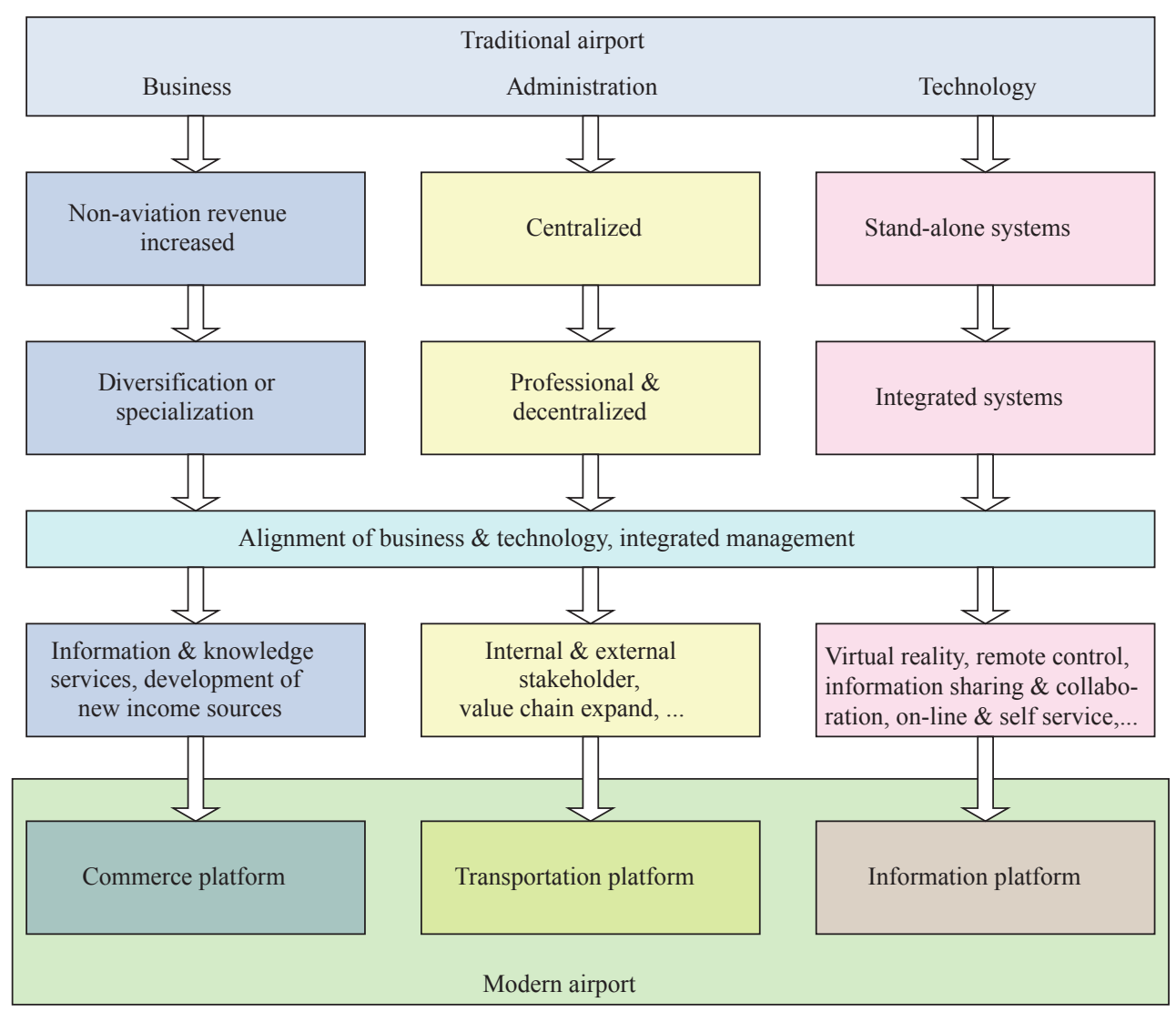

Figure 1. Evolution of airport management model.

the function of expanding resources in the way of resources sharing. Informatization process is not only the update of technology but also the innovation of its correlated management ideal, business lines and cooperation modes, etc.

3.2 Airport multi-platform operation model integrated transportation, commerce and information functions

In the traditional sense "airport" only exists as the platform of air transportation. Its single function is one of reason caused low service efficiency of airport resources. By virtue of exploiting its advantages and possibilities in resources integration, modern airport could boast more functions and play more roles in daily social affairs. Sun and Guo (2011) realized that "on the basis of comprehensive utilization of available resources, airport functions could be expanded to multiple service platform integrated transportation platform, commerce platform and service platform various functions through combining external resource and virtual resources" (p.2395).

As transportation platform, its function focuses on the optimization and expansion of materials flow. Its transportation function not only exists as single air transportation platform but also becomes multi-function transportation platform taking full advantage of mailing facilities and transportation to form standard transportation hubs with integrated multi-mode including air, railway, road and vessel, etc.

As a commerce platform, its function focuses on the optimization and expansion of funds flow. On the commerce operation, airport could combine its own and partner's resources advantages to derivate new functions such as electronic commerce and investment and become commerce platform integrated trading, shopping and transaction, etc. based on expanding non-air business.

As an information platform, its function focuses on the optimization and expansion of information flow. Through optimization and integration, airport could become information platform integrated information gathering, transmission, communication and innovation. Its terminal building, call centre and official website are not only the information platform of the airport business operation but also become information infrastructure shared by passengers, surrounding areas, industries and cooperation partners.

Various functions of the modern airport is the comprehensive service platform, combined physical facilities platform and information technology platform. Meanwhile its functions platform is also the platform of resources integration. Expansion of resources utilization scope and depth as well as promotion of service efficiency accelerates the innovation of operation management. Also it enables the modern airport in the function and form beyond the traditional airport delivering a 


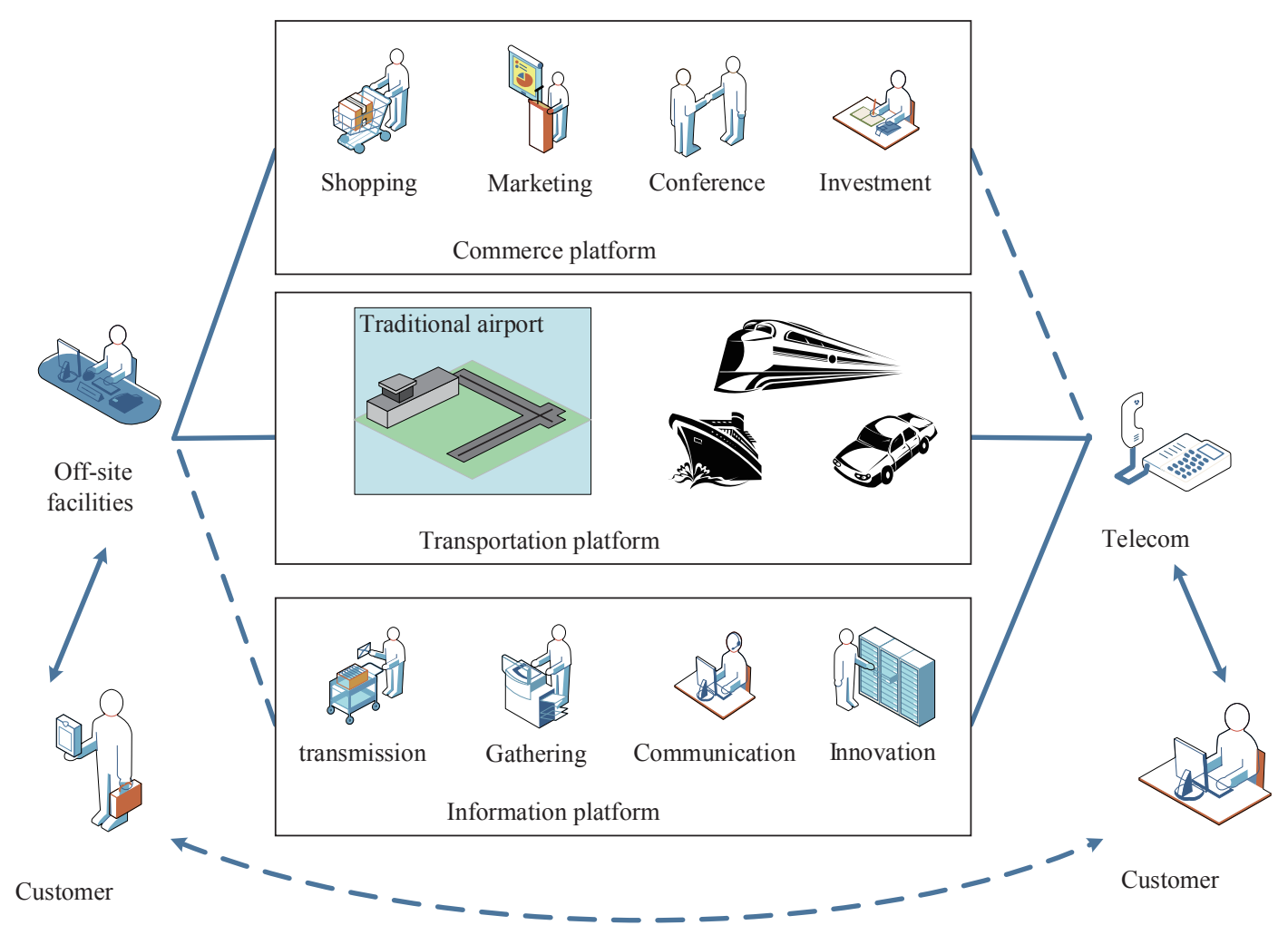

Figure 2. Functions of modern airport.

balanced flow of materials, funds and information.

\section{Implementation process of airport man- agement informatization based on analysis of partners and customers}

Implementation of airport informatization is a comprehensive systematic project and reformation on traditional airport operation model as well as management philosophy. Liu and Sun (2010) suggest that "except for basic information technology application, airport informatization could sum up in 4 aspects: operation management, partner collaboration, public service and integrated innovation" (p.2). Therein operation management is embodied in the optimization and improvement of current business process; partner collaboration strengthens cooperation efficiency among airport correlated organizations; public service is embodied in rendering more humanized service; integrated innovation is business expansion based on sufficient integration of various resources. All these are impact on airport operation management model by informatization application, special attention and positive response during the process of informatization.

Airport informatization is the process of effectively planning and taking full advantage of various resources on the basis of redefining airport functions, comprehensively considering the demands from airport operated partners, customers and various stakeholders. The implementation of informatization should take into account broader airport concept as shown in Figure 3.

Airport informatization is not only pure technology application process but also the process of optimizing the business process and reasonably configuring available resources. Sun and Guo (2011b) have inducted 3 implementation processes: "first is to increase the service efficiency of single resource; second is to promote the ability of 'shortcomings' in the relevant resources; third is to optimize and configure the correlated resources combination" (p. 2391).

4.1 Sufficient utilization of resources and promotion of benefits

Currently most of facilities in the airport are under lower service efficiency, e.g., shopping mall and dinning room in the airport are designed according to daily peak passengers while they are idle during non-busy period. Attracting more clients could give full play to these facilities, dilute fixed cost of airport operation and boost marginal revenue. The following ways could be adopted: enrich the relevant service facilities in the airport, encourage consumption of more customers; further exploit more passenger source, attract non-flying customers such as relatives and friends meeting or seeing off the passengers; supply various commodities and increase entertainment to attract customers to the airport for consumption. In addition, the working staffs in the airport are also an enormous consump- 


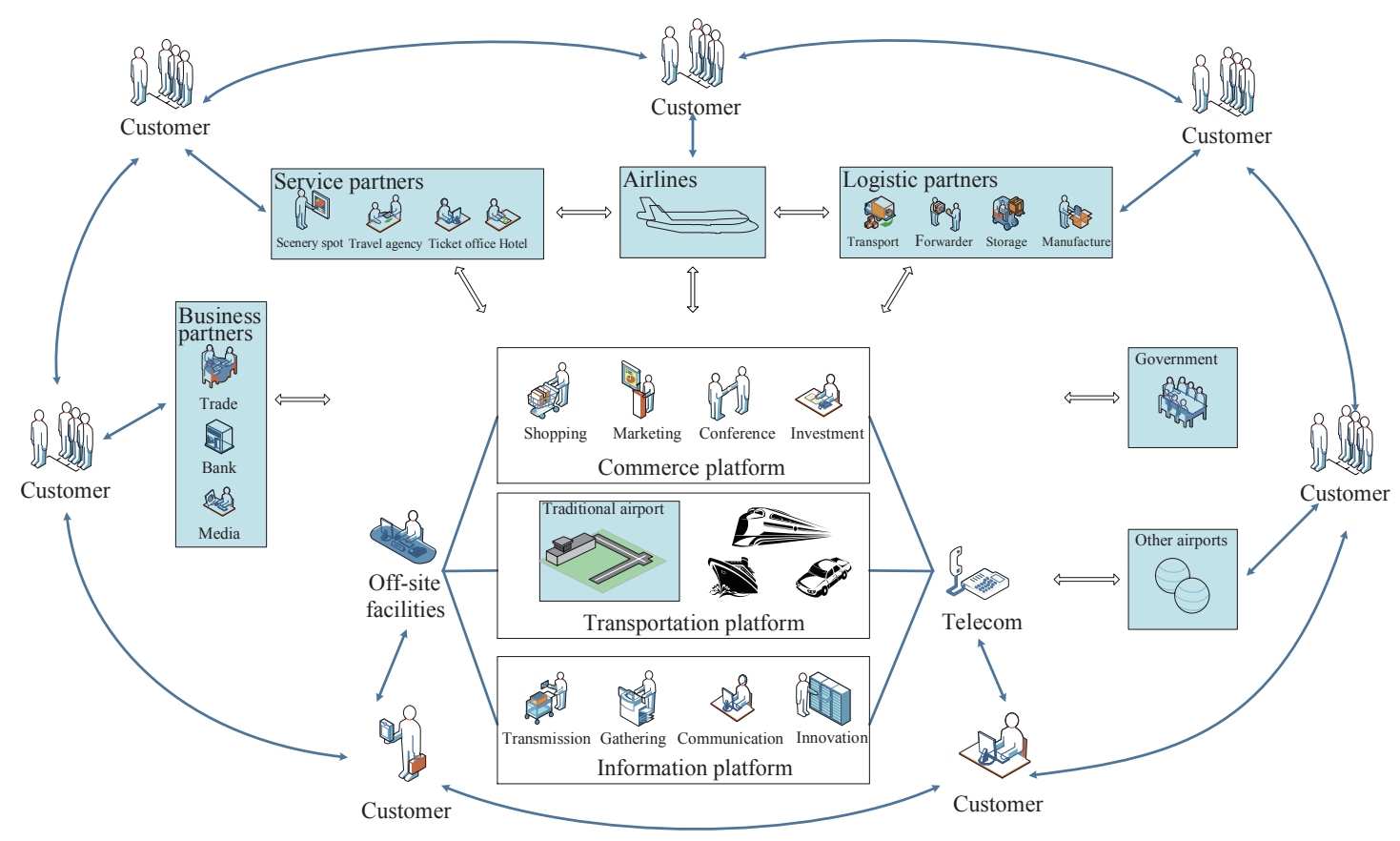

Figure 3. Partners \& customers of modern airport.

tion group including various staff of airport administrative departments, cooperation partners and government institutions; ways to expand airport commerce such as on-line shopping, etc. Materials flow and funds flow in the airport could be optimized greatly to get double results with half the effort. All these could be realized by expanding airport function and effectively integrating virtual resources. Meanwhile it is also the major goal of informatization.

4.2 "Shortcomings" replenishing and comprehensive ability strengthening

Airport is a large-scale project composed of various infrastructures such as the runway and terminal building. Different facilities differ in difficulty, investment and request when making the design and building. Some are completed at once while some are constructed step by step. E.g., airport runway should be completed at once while the terminal building is constructed in stages according to the increase of passengers. Generally the capacity of one runway is 20 million passengers per year while the design capacity of standard terminal building is 3-6 million passengers per year. In accordance with the principle of "Buckets Effect", the capacity of the whole airport is determined by the facility with the lowest capacity. It is major measure to boost the overall capacity how to effectively increase the service efficiency of the facility with low capacity.

To increase airport capacity, the traditional mode is to build more infrastructures while this will increase the overall investment in the airport. In the operation low season huge expenses from fixed cost it still needed to face and the uncertainty as air- port operation is also increased. The effective implementation of informatization is one of the ways to increase airport capacity, adoptable means such as optimization of current business processes and increasing the occupancy rate of facilities. Increases the overall capacity of facilities rely on adopting new technology approaches, breaking through the local bottleneck of resources and boosting the processing capacity of low efficiency link. In addition, more utilization of external resources and completing some links of business process outside the airport also increase the overall capacity of facilities by replenishing "Shortcomings".

\subsection{Process optimization and resources reconfiguration}

Process optimization is namely reasonable configuration of the current resources. Current operation framework is gradually formed during the process of constant development. In this process, the scale of each business process is the only enlarged simply, which will cause repeated investment and lower service efficiency. With the change of customer's demands, some original process can't satisfy their actual demands. Meanwhile, as a result of technological progress, some manual operations could be replaced by technology. Demands and technology changes will lead to changes such as original position setting, resources configuration, report relationship, risk prevention. Therefore drastic changes of airport business process should be carried out in particular period.

Various businesses in the airport are mutually influenced. It is unpractical to realize the maximum benefit of each business. During the process of actual implementation, reasonable 
refusal can reach the best overall benefit. For example, in the expansion of air business although it could reduce the income by lowering the cost of taking off and landing other relevant incomes could be increased with the sufficient utilization of airport resources by increasing flights and passengers.

In the process of satisfying passenger's demands, reasonable scale should be used to ensure the realization of overall benefit. For example, reducing the staying time of passenger in the airport is likely to reduce the commercial income; more services to staffs may result in the contradiction of staff and passenger to share airport facilities. During the process of cooperation with business partners, role conflict and contradiction on distribution of interests may appear. All these problems also should be focused on during the implementation process of airport informatization. Informatization process is also the process of sustained optimization of business process, reasonable configuration and constant adjustment of various resources.

If airport informatization is to reasonably utilize all available resources, exceed the simple correspondence of original resources and function it should continue to exploit the internal potentiality of various resources, fully integrate and effectively share various relevant resources and strive to create a high-efficient utilization of resources to boost the overall benefits. This is the process of constantly discovering the potential value of the airport.

\section{Conclusions}

During the implementation process of engineering informatization, two major problems are faced: one is to support the project life-cycle management; second is to support inter-organizational matching among partners. No matter the planning phase or operation phase, it's all involved in cooperation among relevant organizations. A major goal to implement engineering management informatization is how to lower the organization collaboration cost in the project management and supporting the effective collaboration among different areas, organizations and departments in the ways of technology and management.

How to effectively support project management espe- cially for the management of project operation phase has been emphasized in this article. It's illustrated that airport informatization is the innovation of business model. Technology application through the analysis and study of airport informatization. The function model of the airport is also more abundant. It is diversified through substantially boosting the abilities of resources allocation, communication, risk response and crisis resolving. It also specifically embodies project operation management informatization.

\section{References}

He, J. (2013). On the core of engineering management theory. Engineering Sciences, 15(11), 4-11, 18

Liu, R., \& Sun, K. (2010). Connotation and denotation of engineering management informatization. Science \& Technology Progress and Policy, 27(19), 1-4

Liu, R., \& Sun, K. (2011). Research on architecture of engineering management informatization. Engineering Sciences, 13(8), 4-9

Sun, K. (2012). Concept, characteristics and patterns of inter-organizational information sharing. Chinese Journal of Systems Science, 20(2), 28-33, 61

Sun, K., \& Guo, W. (2011). Airport business model with integrated services platforms for transportation, commerce \& information. Proceedings of the 2nd International Conference on Engineering and Business Management. Wuhan

Sun, K., \& Guo, W. (2011b). Analysis on partners \& customers of airport management informatization. Proceedings of the 2nd International Conference on Engineering and Business Management. Wuhan

Sun, K., \& Lai, W. (2012). Integrated passenger service system for ideal process flow in airports. Przeglad Elektrotechniczny, 03b, 54-59

Sun, K., \& Liu, R. (2012). Research on application model for engineering management informatization. Science \& Technology Progress and Policy, 29(18), 1-6

Sun, K., \& Liu, R. (2013). Information processing theory based inter-organizational information sharing strategy choice. Chinese Journal of Management, 10(2), 293-298

Zhu, G. (2008).Several viewpoints on the informatization of engineering management. Engineering Sciences, 10(12), 32-35 